\title{
Pengaruh Kualitas Pelayanan Terhadap Kepuasan Pasien Rawat Inap di Ruang Perawatan Private Care Center (PCC) RSUP Dr. Wahidin Sudirohusodo Makassar.
}

\author{
Muhammad Rani ${ }^{1}$, Salim Basalamah ${ }^{2}$, Hasanuddin Damis ${ }^{3}$ \\ Magister Manajemen, Universitas Muslim Indonesia.
}

\begin{abstract}
ABSTRAK
Penelitian ini bertujuan untuk mencari bukti emperis variabel-variabel yang mempengaruhi Kepuasan Pasien Rawat Inap di Ruang Perawatan Private Care Center (PCC) RSUP Dr. Wahidin Sudirohusodo Makassar. Untuk melihat pengaruh tersebut digunakan lima variabel independen yaitu Bukti Fisik (tangibles), Kehandalan (reliability), Ketanggapan (responsiveness), Jaminan (assurance), Empati (empathy) serta satu variabel dependen yaitu kepuasan pasien.

Dalam peneltian ini, sampel yang diambil adalah 97 responden. Pengumpulan data dilakukan melalui observasi langsung dan survei dengan cara pembagian kuesioner kepada responden. Penelitian ini menggunakan metode analisis regresi linear berganda.

Hasil penelitian menunjukkan bahwa Bukti Fisik (tangibles) dan Ketanggapan (responsiveness) berpengaruh positif dan signifikan terhadap Kepuasan Pasien Rawat Inap di Ruang Perawatan Private Care Center (PCC) RSUP Dr. Wahidin Sudirohusodo Makassar. Sedangkan Kehandalan (reliability), Jaminan (assurance), dan Empati (empathy) tidak berpengaruh positif dan signifikan terhadap Kepuasan Pasien Rawat Inap di Ruang Perawatan Private Care Center (PCC) RSUP Dr. Wahidin Sudirohusodo Makassar. Disamping itu variabel yang paling dominan berpengaruh terhadap kepuasan Pasien Rawat Inap di Ruang Perawatan Private Care Center (PCC) RSUP Dr. Wahidin Sudirohusodo Makassar adalah Bukti Fisik.
\end{abstract}

Kata Kunci : Bukti Fisik, Kehandalan, Ketanggapan, Jaminan, Empati, Kepuasan Pasien, Analisis Regresi Linear Berganda.

\begin{abstract}
This study aims to find empirical evidence of variables that affect inpatient patient satisfaction in the Private Care Center (PCC) Hospital. Dr. Wahidin Sudirohusodo Makassar. To see this effect five independent variables are used namely Physical Form (tangibles), Reliability, Responsiveness, Assurance, Empathy and one dependent variable is patient satisfaction.

In this study, the sample taken was 97 respondents. Data collected through direct observation and survey by way of distribution questionnaires to respondents. This study uses multiple linear regression analysis method The results showed that the physical form (tangibles) and responsiveness (responsiveness) had a positive and significant effect on the Satisfaction of Inpatients in the Private Care Center (PCC) Room of RSUP Dr. Wahidin Sudirohusodo Makassar. While reliability, assurance, and empathy have no positive and significant effect on patient satisfaction in the Private Care Center (PCC) Hospital. Dr. Wahidin Sudirohusodo Makassar. Besides that, the most dominant variable influences the Satisfaction of Inpatients in the Private Care Center (PCC) Room of RSUP Dr. Wahidin Sudirohusodo Makassar is Physical Evidence (tangibles).
\end{abstract}

Keywords : Tangibles, Reliability, Responsiveness, Assurance, Empathy, Patient Satisfaction, Multiple Linear Regression Analysis. 


\section{PENDAHULUAN}

Dalam meningkatkan taraf kesehatan masyarakat, rumah sakit memegang peranan penting dalam pembangunan kesehatan masyarakat di suatu wilayah karena mencakup penanganan atas kesehatan khalayak (Bustan : 2012). Menurut undangundang Republik Indonesia Nomor : 44 tahun 2009 tentang rumah sakit yang dikutip dari (Mulyadi, Fadli, Ningsih, 2013), dimana rumah sakit merupakan institusi pelayanan kesehatan bagi masyarakat dengan karakteristik tersendiri yang dipengaruhi oleh perkembangan ilmu pengetahuan kesehatan, kemajuan teknologi, dan kehidupan sosial ekonomi masyarakat yang harus tetap mampu meningkatkan pelayanan yang lebih bermutu dan terjangkau oleh masyarakat agar terwujud derajat kesehatan yang setinggi-tingginya.

Rumah sakit memiliki peran yang sangat strategis dalam upaya mempercepat peningkatan derajat kesehatan masyarakat. Paradigma baru pelayanan kesehatan mensyaratkan agar rumah sakit memberikan pelayanan berkualitas sesuai kebutuhan dan keinginan pasien dengan tetap mengacu pada kode etik profesi dan kode etik medis. Seiring dengan perkembangan teknologi yang pesat dan persaingan yang semakin ketat, maka rumah sakit dituntut untuk melakukan upaya-upaya yang dapat meningkatkan kualitas pelayanannya. Karena kualitas merupakan inti kelangsungan hidup sebuah lembaga, dalam hal ini rumah sakit. Gerakan revolusi mutu melalui pendekatan manajemen mutu terpadu menjadi tuntutan yang tidak boleh diabaikan jika suatu lembaga ingin hidup dan berkembang ditengah persaingan yang semakin ketat akhir-akhir ini menuntut sebuah lembaga penyedia jasa/layanan untuk selalu memanjakan pelanggan/konsumen dengan memberikan pelayanan terbaik.

Para konsumen akan mencari produk berupa barang atau jasa dari perusahaan yang dapat memberikan pelayanan yang terbaik kepadanya (Assauri, 2003:25). Masalah utama sebagai sebuah lembaga jasa pelayanan kesehatan adalah semakin banyaknya pesaing. Oleh karena itu, rumah sakit dituntut untuk selalu menjaga kepercayaan konsumen dengan meningkatkan kualitas pelayanan agar kepuasan konsumennya meningkat. Pihak rumah sakit perlu secara cermat menentukan kebutuhan konsumen sebagai upaya untuk memenuhi keinginan dan meningkatkan kepuasan atas pelayanan yang diberikan (John, J., 1992: 57).

Memberikan pelayanan dengan kualitas terbaik, bukanlah sesuatu yang mudah bagi pengelola rumah sakit karena pelayanan yang diberikan oleh rumah sakit menyangkut kualitas hidup para pasiennya sehingga bila terjadi kesalahan dalam tindakan medis dapat berdampak buruk bagi pasien. Dampak tersebut dapat berupa sakit pasien bertambah parah, kecacatan bahkan kematian (Jacobalis, S. 1995: 68).

Rumah sakit sebagai bagian dari sistem kesehatan nasional dituntut untuk meningkatkan kualitas penyediaan fasilitas, pelayanan dan kemandirian. Dengan demikian rumah sakit merupakan salah satu pelaku pelayanan kesehatan yang kompetitif harus dikelola oleh pelaku yang mempunyai jiwa wirausaha yang mampu menciptakan efisiensi, keunggulan dalam kualitas dan pelayanan, keunggulan dalam inovasi serta unggul dalam merespon kebutuhan pasien (Jacobalis, S. 1995: 77). 
Dalam menerima dan melayani pasien rawat inap sebagai konsumen dengan berbagai karakteristik, rumah sakit harus melengkapi diri supaya senantiasa mendengarkan suara konsumen, dan memiliki kemampuan memberikan respon terhadap setiap keinginan, harapan dan tuntutan pengguna jasa sarana pelayanan kesehatan. Hal ini erat berhubungan dengan tenaga kesehatan yang senantiasa mendampingi dan melayani pasien sebagai konsumennya.

Hal tersebut diatas sejalan dengan pendapat yang dikemukakan (Waworuntu, 1997: 19) bahwa "Seseorang yang profesional dalam dunia administrasi negara menguasai kebutuhan masyarakat dan mengetahui cara memuaskan dan memenuhi kebutuhan masyarakat. Masyarakat perlu dipuaskan melalui pemenuhan kebutuhannya. Sehingga masyarakat merasa sebagai seorang raja, maka harus dilayani dengan baik".

Kepuasan konsumen dapat membentuk persepsi dan selanjutnya dapat memposisikan produk perusahaan dimata konsumennya. Dalam hubungannya dengan kepuasan konsumen/pasien dan kualitas pelayanan RSUP dr. Wahidin Sudirohusodo Makassar, masyarakat beberapa kali menyampaikan keluhan terhadap pelayanan RSUP dr. Wahidin Sudirohusodo Makassar, khususnya terhadap kualitas pelayanan rawat inap melalui media masa lokal maupun melalui kotak saran yang ada di RSUP Dr. Wahidin Sudirohusodo Makassar. Hal demikian memberikan indikasi bahwa RSUP Dr. Wahidin Sudirohusodo Makassar yang dibangun dengan sarana dan prasarana cukup memadai belum mampu memberikan pelayanan yang sesuai harapan, keinginan dan tuntutan dari masyarakat sebagai konsumen.

Pasien akan merasa puas apabila ada persamaan antara harapan dan kenyataan pelayanan kesehatan yang diperoleh. Kepuasaan pengguna pelayanan kesehatan mempunyai kaitan yang erat dengan hasil pelayanan kesehatan, baik secara medis maupun non medis seperti kepatuhan terhadap pengobatan, pemahaman terhadap informasi medis dan kelangsungan perawatan (Kotler, 1997: 82).

Untuk membuktikan pernyataan diatas, penulis akan mengadakan suatu penelitian secara mendalam tentang beberapa faktor yang berpengaruh terhadap kepuasan pasien dengan judul "Pengaruh Kualitas Pelayanan Terhadap Kepuasan Pasien Rawat Inap di Ruang Perawatan Private Care Center (PCC) RSUP Dr. Wahidin Sudirohusodo Makassar".

\section{Rumusan Masalah}

Berdasarkan uraian latar belakang di atas, maka rumusan masalah dalam penelitian ini adalah:

1. Apakah bukti fisik berpengaruh terhadap kepuasan pasien rawat inap di ruang perawatan Private Care Center (PCC) RSUP Dr. Wahidin Sudirohusodo Makassar.

2. Apakah kehandalan berpengaruh terhadap kepuasan pasien rawat inap di ruang perawatan Private Care Center (PCC) RSUP Dr. Wahidin Sudirohusodo Makassar.

3. Apakah ketanggapan berpengaruh terhadap kepuasan pasien rawat inap di ruang perawatan Private Care Center (PCC) RSUP Dr. Wahidin Sudirohusodo Makassar.

4. Apakah jaminan berpengaruh terhadap kepuasan pasien rawat inap di ruang perawatan Private Care Center (PCC) RSUP Dr. Wahidin Sudirohusodo Makassar. 
5. Apakah empati berpengaruh terhadap kepuasan pasien rawat inap di ruang perawatan Private Care Center (PCC) RSUP Dr. Wahidin Sudirohusodo Makassar.

6. Variabel apa yang dominan mempengaruhi kepuasan pasien rawat inap di ruang perawatan Private Care Center (PCC) RSUP Dr. Wahidin Sudirohusodo Makassar.

\section{Tujuan Penelitian}

1. Untuk menganalisis pengaruh kualitas pelayanan terhadap kepuasan pasien rawat inap di ruang perawatan Private Care Center (PCC) RSUP Dr. Wahidin Sudirohusodo Makassar

2. Untuk menganalisis variabel yang paling dominan mempengaruhi terhadap kepuasan pasien rawat inap di ruang perawatan Private Care Center (PCC) RSUP Dr. Wahidin Sudirohusodo Makassar.

\section{TINJAUAN PUSTAKA}

\section{TINJAUAN UMUM TENTANG KEPUASAN PASIEN}

Kepuasan pasien tergantung pada kualitas pelayanan yang didapatkan. Pelayanan adalah semua upaya yang dilakukan untuk memenuhi keinginan pelanggannya dengan jasa yang akan diberikan. Suatu pelayanan dikatakan baik oleh pasien, ditentukan oleh kenyataan apakah jasa yang diberikan bisa memenuhi kebutuhan pasien, dengan menggunakan persepsi pasien tentang pelayanan yang diterima (memuaskan atau mengecewakan, juga termasuk lamanya waktu pelayanan). Kepuasan dimulai dari penerimaan terhadap pasien dari pertama kali datang, sampai pasien meninggalkan rumah sakit. Dalam hal ini, prosedur penerimaan pasien merupakan pelayanan yang pertama diberikan oleh rumah sakit dan merupakan pengalaman yang selalu diingat oleh pasien (past experience) yang merupakan salah satu penentu persepsi pasien terhadap pelayanan kesehatan di rumah sakit tersebut. Dengan demikian jelas bahwa kontak pertama antara petugas rumah sakit dengan pasien menjadi catatan yang sangat penting bagi pasien dalam memberikan penilaian kepuasan pasien terhadap pelayanan yang didapatkannya (Supriyanto dan Ernawaty, 2010).

\section{TINJAUAN UMUM TENTANG KUALITAS PELAYANAN}

Pelayanan disuatu rumah sakit harus ditunjang dengan mutu pelayanan yang baik. Rumah sakit secara berkesinambungan meningkatkan kualitas mutu pelayanan karena hal ini yang membuat pelanggan ada rasa puas terhadap rumah sakit. Salah satu pendekatan kualitas pelayanan yang banyak dijadikan acuan riset pemasaran adalah SERVQUAL (Service Quality) yang dkembangkan oleh (Parasuraman, Zeithaml, dan Berry, 1998), disimpulkan bahwa terdapat sepuluh dimensi SERVQUAL yaitu: competence, access, courtesy, communication, credibility, tangibles, reliability, responsiveness, assurance dan empathy, Penggunaan kesepuluh unsur (dimensi) tersebut dalam perkembangan selanjutnya dimensi yang ada dapat dirangkum menjadi lima dimensi pokok dan dalam penelitian ini dapat dilihat dari indikator sebagai berikut :

1. Bukti langsung (tangible), meliputi fasilitas fisik, perlengkapan, dan pegawai, indikator untuk dimensi ini adalah:

a. tentang bangunan yang digunakan 
b. tentang desain interior

c. tentang peralatan yang digunakan

d. tentang kapasitas lahan parkir yang digunakan

e. tentang lokasi

f. tentang petugas dalam memberikan informasi

g. tentang petugas dalam memberikan solusi

2. Keandalan (reliability), yakni kemampuan memberikan pelayanan yang dijanjikan dengan segera, akurat, dan memuaskan, indikator untuk dimensi reliability adalah:

a. tentang kepercayaan terhadap jasa yang diberikan Suzanto, Kualitas Jasa Pelayanan 31

b. tentang tingkat ketepatan dan kesesuaian antara informasi dengan layanan yang dilaksanakan

c. tentang pemenuhan janji

3. Daya tanggap (responsiveness), yaitu keinginan para staf untuk membantu para pelanggan dan memberikan pelayanan dengan tanggap, indikator untuk dimensi ini adalah:

a. tentang kesiapan dalam rangka melayani pelanggan

b. tentang pelayanan yang diberikan

c. tentang pelayanan yang diberikan apabila menghadapi suatu kendala

4. Jaminan (assurance), mencakup pengetahuan, kemampuan, kesopanan dan sifat dapat dipercaya yang dimiliki oleh para staf, indikator untuk dimensi ini adalah :

a. tentang keramahan pada saat memberikan pelayanan

b. tentang penampilan karyawan ketika melayani pelanggan

c. tentang penggunaan busana saat melayani pelanggan

d. tentang perlakuan khusus terhadap pelanggan

e. tentang kemampuan petugas dalam bidang analisa

f. tentang reputasi tempat bekerja

5. Empati (empathy), meliputi kemudahan dalam melakukan hubungan, perhatian pribadi, dan memahami kebutuhan para pelanggan, indikator untuk dimensi ini adalah:

a. tentang petugas dalam memberikan informasi mengenai produk jasa

b. tentang petugas dalam memberikan solusi

Pelayanan kesehatan yang berkualitas adalah pelayanan kesehatan dengan tingkat kepuasan rata-rata penduduk serta penyelenggaraannya sesuai dengan kode etik dan standar pelayanan profesi yang ada. Dansky mengatakan bahwa pemuasan pelanggan atau pasien adalah prinsip dasar manajemen mutu kualitas. Kualitas pelayanan kesehatan sebenarnya menunjukkan kepada penampilan (performance) dari pelayanan kesehatan. Secara umum disebutkan bahwa makin sempurna penampilan pelayanan kesehatan, makin sempurna pula kualitasnya. Penampilan merupakan keluaran (output) dipengaruhi oleh a) proses (proces) meliputi tindakan medis dan non-medis sesuai dengan standar (standar of cunduct), b) masukan (input) yang meliputi tenaga, dana, sarana serta c) lingkungan (environment) meliputi kebijakan, organisasi dan manajemen. 


\section{TINJAUAN UMUM TENTANG RAWAT INAP}

Rawat inap adalah pelayanan kesehatan perorangan yang meliputi observasi, diagnosa, pengobatan, keperawatan, rehabilitasi medik, dengan menginap di ruang rawat inap pada sarana kesehatan rumah sakit pemerintah dan swasta serta Puskesmas perawatandan rumah bersalin, yang oleh karena penyakitnya penderita harus menginap. Untuk tiap-tiap rumah sakit akan mempunyai ruang an dengan nama sendiri-sendiri sesuai dengan tingkat pelayanan dan fasilitas yang diberikan oleh pihak rumah sakit kepada pasiennya (Kemenkes RI, 2012).

Rawat inap rumah sakit merupakan sarana pelayanan kesehatan yang memberikan pelayanan keperawatan dan pengobatan kepada pasien secara berkesinambungan lebih dari 24 jam. Fasilitas rawat inap rumah sakit merupakan bagian dari rumah sakit yang mempunyai fungsi vital dalam memberikan pelayanan kesehatan bagi pasien, terdapat berbagai ketentuan dan persyaratan dalam merancang sebuah ruang rawat inap rumah sakit untuk memperoleh sebuah ruang rawat inap yang memadai dalam memberikan pelayanan kesehatan.

Dalam rawat inap, catatan yang penting dalam perawatan medis adalah minimal memuat identitas pasien, pemeriksaan, diagnosis/ masalah, persetujuan tindakan medis (bila ada), tindakan pengobatan dan pelayanan lain yang telah diberi kepada pasien (Wildan et al. 2008).

\section{TINJAUAN UMUM TENTANG RUMAH SAKIT}

Rumah sakit dalam perjalanan sejarahnya mengalami perkembangan yang berpengaruh terhadap fungsi dan perannya. Rumah sakit berfungsi untuk mempertemukan dua tugas prinsip yang membedakan dengan lembaga lainnya yang melakukan kegiatan pelayanan jasa. Pada prinsipnya rumah sakit merupakan institusi yang mempertemukan tugas yang didasari oleh dalil-dalil etik medik, karena merupakan tempat bekerjanya para profesional para penyandang lafal sumpah medik dalam melakukan tugas profesionalnya. Selain itu, rumah sakit juga bertindak sebagai institusi yang bergerak dalam hubungan-hubungan hukum dengan masyarakat atau pasien yang tunduk pada norma hukum dan norma etik masyarakat.

Rumah sakit sebagai salah satu fasilitas pelayanan kesehatan perorangan merupakan bagian dari sumber daya kesehatan yang sangat diperlukan dalam mendukung penyelenggaraan upaya kesehatan. Pada hakekatnya rumah sakit berfungsi sebagai tempat penyembuhan penyakit dan pemulihan kesehatan. Fungsi dimaksud memiliki makna tanggung jawab yang seyogyanya merupakan tanggung jawab pemerintah dalam meningkatkan taraf kesejahteraan masyarakat. Untuk optimalisasi hasil serta kontribusi positif tersebut, harus dapat diupayakan masuknya upaya kesehatan sebagai asas pokok program pembangunan nasional (Kementerian Kesehatan RI, 2012).

\section{KERANGKA KONSEPTUAL DAN HIPOTESIS}

\section{A. Kerangka Konseptual}

Kerangka konseptual merupakan sintesa tentang hubungan antara variabel yang 
disusun dari berbagai teori yang telah dideskripsikan (Sugiyono, 2008:89).

Dari kerangka konsep dalam penelitian ini ada dua macam variabel yang akan dianalisa, yaitu variabel bebas, yang menjadi pokok masalah yang diteliti yaitu kualitas pelayanan yang dimensinya terdiri dari bukti fisik (tangibles), kehandalan (reliablility), ketanggapan (responsiveness), jaminan (assurance), empati (empathy), dan variabel terikat, variabel yang besarnya dipengaruhi oleh variabel bebas yaitu kepuasan pasien di rawat inap Private Care Center (PCC) RSUP dr. Wahidin Sudirohusodo Makassar. Tiap-tiap konsep masing-masing mempunyai variabelvariabel sebagai indikasi pengukuran masing-masing konsep tersebut. Oleh karena itu kerangka konsep dalam penelitian ini dapat digambarkan sebagai berikut:

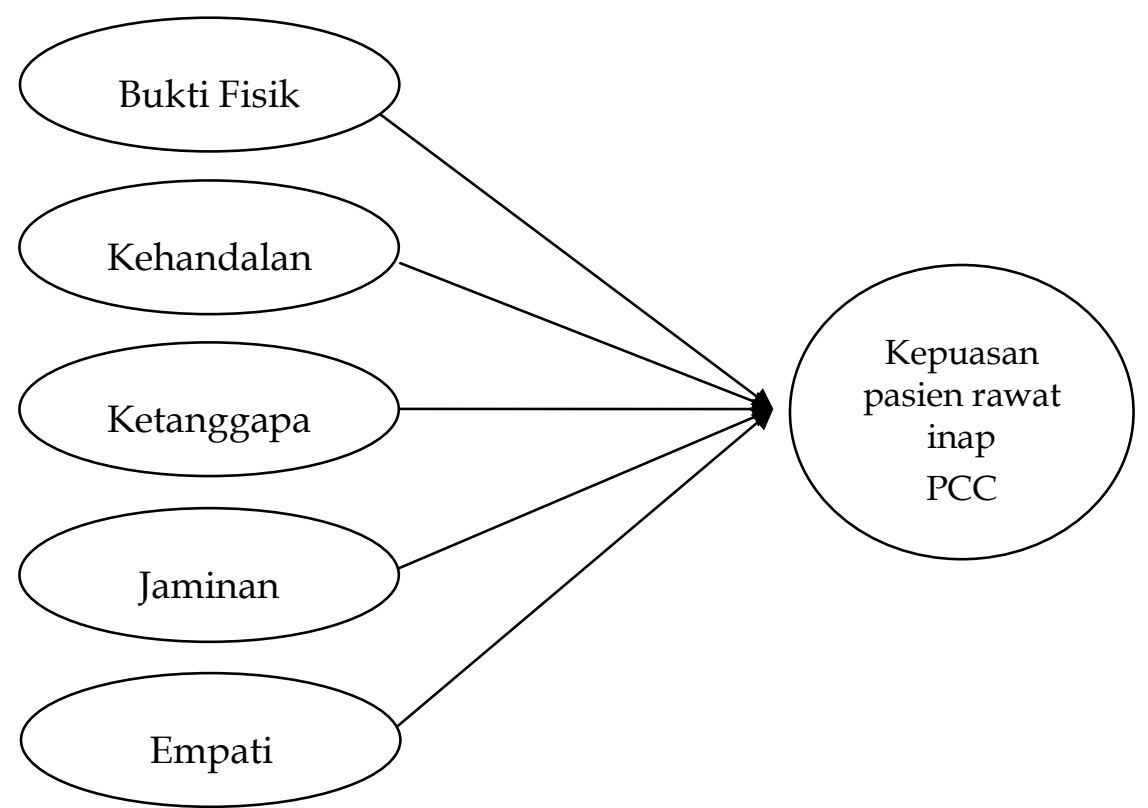

Gambar 2.1 Kerangka Konseptual

\section{B. Hipotesis}

Berdasarkan teori dan kerangka konseptual diatas dapat dikemukakan perumusan hipotesis penelitian sebagai berikut :

1. Bukti fisik (tangibles) berpengaruh signifikan terhadap kepuasan pasien di rawat inap Private Care Center (PCC) RSUP dr. Wahidin Sudirohusodo Makassar.

2. Kehandalan (reliablility) berpengaruh signifikan terhadap kepuasan pasien di rawat inap Private Care Center (PCC) RSUP dr. Wahidin Sudirohusodo Makassar.

3. Ketanggapan (responsiveness) berpengaruh signifikan terhadap kepuasan pasien di rawat inap Private Care Center (PCC) RSUP dr. Wahidin Sudirohusodo Makassar.

4. Jaminan (assurance) berpengaruh signifikan terhadap kepuasan pasien di rawat inap Private Care Center (PCC) RSUP dr. Wahidin Sudirohusodo Makassar.

5. Empati (empathy) berpengaruh signifikan terhadap kepuasan pasien di rawat inap Private Care Center (PCC) RSUP dr. Wahidin Sudirohusodo Makassar.

6. Empati (empathy) merupakan variabel yang dominan mempengaruhi kepuasan pasien rawat inap di ruang perawatan Private Care Center (PCC) RSUP Dr. Wahidin Sudirohusodo Makassar. 


\section{METODE PENELITIAN}

\section{A. Pendekatan Penelitian}

Penelitian ini menggunakan tipe/pendekatan kuantitatif yang didasarkan pada aliran pemikiran posivistik dengan proses penelitian yang bersifat deduktif. Dengan pendekatan ini, diharapkan hasil yang diperoleh di lokasi sampel penelitian dapat dijadikan sebagai generalisasi terhadap populasi yang telah ditetapkan.

\section{B. Waktu dan lokasi penelitian}

Waktu yang digunakan dalam penelitian ini kurang lebih tiga bulan lamanya mulai bulan April sampai Juni 2019. Penelitian dilakukan di Perawatan Rawat Inap Private Care Center (PCC) RSUP dr. Wahidin Sudirohusodo Makassar dengan pertimbangan penulis adalah karyawan pada instansi tersebut di atas.

\section{Jenis dan Sumber Data}

Jenis dan sumber data yang akan digunakan dalam penyusunan tesis ini adalah sebagai berikut :

1. Data Primer yaitu data yang diperoleh dengan mengadakan pengamatan serta wawancara secara langsung pada pasien rawat inap Private Care Center (PCC) RSUP dr. Wahidin Sudirohusodo Makassar.

2. Data Sekunder yaitu data yang diperoleh dengan jalan mengumpulkan dokumendokumen atau arsip-arsip perusahaan serta informasi lainnya yang ada hubungannya dengan masalah di RSUPDr.Wahidin Sudirohusodo Makassar.

\section{Teknik Pengumpulan Data}

Untuk memperoleh hasil penelitian yang diharapkan, diperlukan data-data informasi yang mendukung penelitian. Untuk keperluan tersebut penulis menggunakan metode pengumpulan data berupa :

\section{Observasi}

Pengamatan secara langsung terhadap objek penelitian untuk memperoleh informasi tentang kegiatan yang berkaitan dengan masalah yang diteliti.

\section{Wawancara}

Merupakan proses untuk memperoleh keterangan melalui tanya jawab dengan pihak-pihak yang terkait.

\section{Kuesioner}

Teknik pengumpulan data dengan cara menyebarkan angket yang berisi daftar pertanyaan yang harus diisi oleh para responden. Informasi atau data yang diperoleh dari jawaban kuesioner ini dijadikan sebagai sumber informasi utama untuk melakukan analisis hasil penelitian. Penyebaran angket kepada pihak-pihak yang mempunyai peranan dengan masalah yang diteliti.

\section{Dokumentasi}

Teknik pengumpulan data dengan cara menyebarkan angket yang berisi daftar pertanyaan yang harus diisi oleh para responden. Informasi atau data yang 
diperoleh dari jawaban kuesioner ini dijadikan sebagai sumber informasi utama untuk melakukan analisis hasil penelitian.

\section{E. Populasi dan Sampel}

Populasi adalah wilayah generalisasi yang terdiri atas objek atau subjek yang memiliki kualitas dan karakteristik tertentu yang ditetapkan oleh peneliti untuk dipelajari dan kemudian ditarik kesimpulannya (Sugiyono, 2008). Populasi pada penelitian ini adalah pasien rawat inap Instalasi Private Care Center (PCC) RSUP Dr. Wahidin Sudirohusodo Makassar. Populasi dalam penelitian ini berjumlah 2.740 orang pasien (Desember 2018).

Sampel merupakan bagian dari jumlah dan karakterisitik yang dimiliki oleh suatu populasi yang akan diteliti. Penentuan sampel dalam penelitian ini dilakukan dengan jenis Non Probability Sampling. Non Probability Sampling jenis sampel ini tidak dipilih secara acak. Tidak semua unsur atau elemen populasi mempunyai kesempatan sama untuk bisa dipilih menjadi sampel. Teknik Non Probability Sampling yang dipilih yaitu dengan Convenience Sampling yaitu responden sebagai sampel berdasarkan kebetulan, yaitu siapa saja yang secara kebetulan bertemu dengan peneliti dapat digunakan sebagai sampel bila orang yang kebetulan ditemui cocok sebagai sumber data (Sugiyono, 2004). Keuntungan dari pada teknik ini adalah terletak pada ketepatan peneliti memilih sumber data sesuai dengan variabel yang diteliti (Arikunto, 2002).

Dari populasi yang ada, ukuran sampel minimum diperoleh dengan menggunakan rumus Slovin (Umar, 2003), sebagai berikut :

Keterangan:

$$
n=\frac{N}{1+N e^{2}}
$$

$$
\begin{aligned}
& \mathrm{n}=\text { Ukuran Sampel } \\
& \mathrm{N}=\text { Ukuran populasi } \\
& \mathrm{e}=\text { Persen kelonggaran ketidakpastian karena kesalahan pengambilan } \\
& \text { sampel yang masih dapat ditolerir, maksimum sebesar } 5 \% .
\end{aligned}
$$

Berdasarkan rumus Slovin di atas, maka ukuran sampel minimum pada masing-masing cabang adalah sebagai berikut :

$$
\begin{aligned}
& n=\frac{2740}{1+2740(0.1)^{2}}=96.48 \\
& \text { Jadi jumlah sampel adalah } 97 \text { orang }
\end{aligned}
$$

\section{F. Metode Analisis}

\section{Analisis Kualitatif}

Metode yang lebih menekankan pada aspek pemahaman secara mendalam terhadap suatu masalah daripada melihat permasalahan untuk penelitian generalisasi. Metode penelitian ini lebih suka menggunakan teknik analisis mendalam (in-depth analysis), yaitu mengkaji masalah secara kasus perkasus karena metodologi kulitatif yakin bahwa sifat suatu masalah satu akan berbeda dengan sifat dari masalah lainnya. Tujuan dari metodologi ini bukan suatu generalisasi tetapi pemahaman secara mendalam terhadap suatu masalah. 


\section{Analisis Kuantitatif}

Adalah metode yang lebih menekankan pada aspek pengukuran secara obyektif terhadap fenomena sosial. Untuk dapat melakukan pengukuran, setiap fenomena sosial dijabarkan kedalam beberapa komponen masalah, variable dan indikator. Setiap variabel yang di tentukan diukur dengan memberikan simbol angka yang berbeda-beda sesuai dengan kategori informasi yang berkaitan dengan variabel tersebut. Tujuan utama data metodologi ini ialah menjelaskan suatu masalah tetapi menghasilkan generalisasi.

\section{Analisis Deskriptif}

Data yang sifatnya berupa dokumen-dokumen dari RSUP Dr. Wahidin Sudirohusodo Makassar. Adapun data yang diperoleh dari pendekatan empiris dianalisis secara kuantitatif dengan menggunakan teknik pengujian uji multiple regression (regresi berganda), yang dihitung dengan menggunakan perangkat lunak (software) program komputer.

\section{Analisis Regresi Berganda}

Adapun data yang diperoleh dari pendekatan empiris dianalisis secara kuantitatif dengan menggunakan teknik pengujian uji multiple regression (regresi berganda), yang dihitung dengan menggunakan perangkat lunak (software) berupa paket program komputer.

Penggunaan model uji multiple regression, akan membantu untuk melakukan identifikasi setiap variasi independen yang diteliti, sehingga tampak variabel mana dari variabel bebas yang sangat berpengaruh terhadap dependen variabel, baik secara parsial maupun secara serempak.

Adapun prosedur analisis data dalam penelitian menggunakan analisis regresi linier berganda dengan menggunakan uji statistik baik uji $F$ maupun uji $t$ dengan formulasi sebagai berikut :

$Y=b_{0}+b_{1} X_{1}+b_{2} X_{2}+b_{3} X_{3}+b_{4} X_{4}+b_{5} X_{5}+e_{i}$

Dimana :

$$
\begin{array}{ll}
\mathrm{Y} & =\text { Kepuasan Pasien } \\
\mathrm{X}_{1} & =\text { Bukti fisik (tangibles) } \\
\mathrm{X}_{2} & =\text { Kehandalan (reliablitity) } \\
\mathrm{X}_{3} & =\text { Ketanggapan (responsiveness) } \\
\mathrm{X}_{4} & =\text { Jaminan (assurance) } \\
\mathrm{X}_{5} & =\text { Empati (empathy) } \\
\mathrm{b}_{0} & =\text { Konstanta } \\
\mathrm{b}_{1, \mathrm{~s} / \mathrm{d} \mathrm{b} \mathrm{b}_{5}}=\text { Koefisien regresi. } \\
\mathrm{e}_{\mathrm{i}} & =\text { Faktor kesalahan }
\end{array}
$$


a. Uji F

Untuk melakukan pengujian terhadap hipotesis pertama, dilakukan uji $\mathrm{F}$, yakni uji Kirelatif, hal ini dimaksudkan untuk mengetahui variabel empati. Uji bermakna jika $\mathrm{F}$ - hitung $>\mathrm{F}$ - tabel dengan tingkat kepercayaan $95 \%$ atau $\mathrm{P}<0,05$, dengan demikian hasilnya adalah tolak $\mathrm{H}_{\mathrm{o}}$ dan terima $\mathrm{H}_{\mathrm{a}}$. Sebaliknya jika $\mathrm{P}>0,05$ maka terima $\mathrm{H}_{\mathrm{o}}$ dan tolak $\mathrm{H}_{\mathrm{a}}$.

Uji F ini dilakukan untuk melihat pengaruh variabel-variabel independen secara keseluruhan terhadap variabel dependen.

b. Uji t

Uji t ini dilaksanakan untuk melihat signifikasi dari pengaruh independen secara individu terhadap variabel dependen dengan menganggap variabel lain bersifat konstan. Uji ini dilaksanakan dengan membandingkan t-hitung dengan $\mathrm{t}$ tabel.

\section{G. Definisi Operasional dan pengukurannya}

Definisi operasional variabel pada penelitian ini adalah variabel kualitas pelayanan kesehatan sebagai variabel bebas (independen) dan kepuasan pasien sebagai variabel terikat (dependen).

1. Variabel Independen (Variabel Bebas)

2. Variabel Dependen (Terikat)

\section{HASIL DAN PEMBAHASAN}

\section{A. Uji Kualitas Data}

\section{Uji Validitas}

Uji validitas penelitian ini digunakan untuk mengetahui apakah pernyataan pada kuesioner penelitian dapat mengukur variabel yang akan diukur. Untuk mengetahui validitas pernyataan dari setiap variabel, maka digunakan correlation bivariate dengan kriteria

a. Jika sig. (2-tailed) $<0,1=$ valid

b. Jika sig. $(2$-tailed $)>0,1=$ tidak valid

Signifikansi dari uji validitas ini dapat dilihat dari kolom total dari setiap item pertanyaan/pernyataan dari kuesioner penelitian.

\section{a. Bukti Fisik}

Hasil uji validitas variabel Bukti Fisik dapat dilihat pada tabel 12 berikut:

Tabel 12; Hasil Uji Validitas Variabel Bukti Fisik

\begin{tabular}{llr|r|r|r|r|}
\hline & \multicolumn{1}{c|}{ X1.1 } & X1.2 & X1.3 & X1.4 & Bukti_Fisik \\
\hline X1.1 & Pearson Correlation & 1 & $.501^{* *}$ & $.565^{* *}$ & $.614^{* *}$ & $.839^{* *}$ \\
& Sig. (2-tailed) & &, 000 &, 000 &, 000 &, 000 \\
& N & 97 & 97 & 97 & 97 & 97 \\
\hline X1.2 & Pearson Correlation & $.501^{* *}$ & 1 & $.373^{* *}$ & $.428^{* *}$ & $.681^{* *}$ \\
& Sig. (2-tailed) &, 000 & &, 000 &, 000 &, 000 \\
& N & 97 & 97 & 97 & 97 & 97 \\
\hline X1.3 & Pearson Correlation & $.565^{* *}$ & $.373^{* *}$ & 1 & $.673^{* *}$ & $.828^{* *}$ \\
\hline
\end{tabular}


Pengaruh Kualitas Layanan... (Rani, Basalamah \& Damis) | 106

\begin{tabular}{llrrrrr} 
& Sig. (2-tailed) &, 000 &, 000 & &, 000 &, 000 \\
& N & 97 & 97 & 97 & 97 & 97 \\
\hline X1.4 & Pearson Correlation & $.614^{* *}$ & $.428^{* *}$ & $.673^{* *}$ & 1 & $.859^{* *}$ \\
& Sig. (2-tailed) &, 000 &, 000 &, 000 & &, 000 \\
& N & 97 & 97 & 97 & 97 & 97 \\
\hline Bukti_ & Pearson Correlation & $.839^{* *}$ & $.681^{* *}$ & $.828^{* *}$ & $.859^{* *}$ & 1 \\
Fisik & Sig. (2-tailed) &, 000 &, 000 &, 000 &, 000 & \\
& N & 97 & 97 & 97 & 97 & 97 \\
\hline
\end{tabular}

Sumber : Output SPSS17.0,2019

Pada tabel 12 tampak bahwa nilai sig.(2-tailed) untuk setiap pertanyaan/pernyataan variabel bukti fisik mempunyai nilai $<0,1$. Nilai tersebut menunjukkan bahwa setiap item pertanyaan/pernyataan dikatakan valid dan dapat dijadikan alat ukur yang tepat.

\section{b. Kehandalan}

Hasil uji validitas variabel Kehandalan dapat dilihat pada tabel 13 berikut:

Tabel 13; Hasil Uji Validitas Variabel Kehandalan

\begin{tabular}{|c|c|c|c|c|c|c|}
\hline & & $\mathrm{X} 2.1$ & $\mathrm{X} 2.2$ & $\mathrm{X} 2.3$ & $\mathrm{X} 2.4$ & Kehandalan \\
\hline \multirow[t]{3}{*}{$\mathrm{X} 2.1$} & Pearson Correlation & 1 & $.393^{* *}$ & $.583^{* *}$ & $.403^{* *}$ & $.810^{* *}$ \\
\hline & Sig. (2-tailed) & & ,000 & ,000 & 000 & ,000 \\
\hline & $\mathrm{N}$ & 97 & 97 & 97 & 97 & 97 \\
\hline \multirow[t]{3}{*}{$\mathrm{X} 2.2$} & Pearson Correlation & $.393^{* *}$ & 1 & $.421^{* *}$ & $.294^{* *}$ & $.683^{* *}$ \\
\hline & Sig. (2-tailed) & ,000 & & ,000 & ,003 & ,000 \\
\hline & $\mathrm{N}$ & 97 & 97 & 97 & 97 & 97 \\
\hline \multirow[t]{3}{*}{$\mathrm{X} 2.3$} & Pearson Correlation & $.583^{* \star}$ & $.421^{* *}$ & 1 & $.494^{* *}$ & $.823^{* *}$ \\
\hline & Sig. (2-tailed) & ,000 & ,000 & & ,000 & ,000 \\
\hline & $\mathrm{N}$ & 97 & 97 & 97 & 97 & 97 \\
\hline \multirow[t]{3}{*}{$\mathrm{X} 2.4$} & Pearson Correlation & $.403^{* *}$ & $.294^{* *}$ & $.494^{* *}$ & 1 & $.709^{* *}$ \\
\hline & Sig. (2-tailed) & ,000 & ,003 & ,000 & & ,000 \\
\hline & $\mathrm{N}$ & 97 & 97 & 97 & 97 & 97 \\
\hline \multirow[t]{3}{*}{ Kehandalan } & Pearson Correlation & $.810^{* *}$ & $.683^{* *}$ & $.823^{* *}$ & $.709^{* *}$ & 1 \\
\hline & Sig. (2-tailed) & ,000 & ,000 & ,000 & ,000 & \\
\hline & $\mathrm{N}$ & 97 & 97 & 97 & 97 & 97 \\
\hline
\end{tabular}

Sumber : Output SPSS17.0,2019

\section{c. Ketanggapan}

Hasil uji validitas variabel ketanggapan dapat dilihat pada tabel 14 berikut:

Tabel 14; Hasil Uji Validitas Variabel Ketanggapan

\begin{tabular}{|c|c|c|c|c|c|c|}
\hline & & X3.1 & X3.2 & X3.3 & X3.4 & Ketanggapan \\
\hline \multirow[t]{4}{*}{$\mathrm{X} 3.1$} & Pearson & 1 & $.669^{* *}$ & $.444^{* *}$ & $.567^{* *}$ & $.799^{* \star}$ \\
\hline & Correlation & & & & & \\
\hline & Sig. (2-tailed) & & ,000 & ,000 & ,000 & ,000 \\
\hline & $\mathrm{N}$ & 97 & 97 & 97 & 97 & 97 \\
\hline X3.2 & $\begin{array}{l}\text { Pearson } \\
\text { Correlation }\end{array}$ & $.669^{* *}$ & 1 & $.528^{* *}$ & $.711^{* *}$ & $.881^{* *}$ \\
\hline
\end{tabular}




\begin{tabular}{|c|c|c|c|c|c|c|}
\hline & Sig. (2-tailed) & ,000 & & ,000 & ,000 & ,000 \\
\hline & $\mathrm{N}$ & 97 & 97 & 97 & 97 & 97 \\
\hline \multirow[t]{4}{*}{ X3.3 } & Pearson & $.444^{* *}$ & $.528^{* *}$ & 1 & $.602^{* *}$ & $.766^{* *}$ \\
\hline & Correlation & & & & & \\
\hline & Sig. (2-tailed) & ,000 & ,000 & &, 000 & ,000 \\
\hline & $\mathrm{N}$ & 97 & 97 & 97 & 97 & 97 \\
\hline \multirow[t]{4}{*}{ X3.4 } & Pearson & $.567^{\star *}$ & $.711^{* *}$ & $.602^{* *}$ & 1 & $.876^{* *}$ \\
\hline & Correlation & & & & & \\
\hline & Sig. (2-tailed) & ,000 & ,000 & ,000 & & ,000 \\
\hline & $\mathrm{N}$ & 97 & 97 & 97 & 97 & 97 \\
\hline \multirow[t]{4}{*}{ Ketanggapan } & Pearson & $.799^{* *}$ & $.881^{* *}$ & $.766^{* *}$ & $.876^{* *}$ & 1 \\
\hline & Correlation & & & & & \\
\hline & Sig. (2-tailed) &, 000 & ,000 & ,000 & ,000 & \\
\hline & $\mathrm{N}$ & 97 & 97 & 97 & 97 & 97 \\
\hline
\end{tabular}

Sumber : Output SPSS17.0,2019

\section{d. Jaminan}

Hasil uji validitas variabel jaminan dapat dilihat pada tabel 15 berikut:

Tabel 15; Hasil Uji Validitas Variabel Jaminan

\begin{tabular}{llrrr|rrrr}
\hline & & X4.1 & X4.2 & X4.3 & X4.4 & Jaminan \\
\hline X4.1 & Pearson Correlation & 1 & $.686^{* *}$ & $.268^{* *}$ & $.456^{* *}$ & $.781^{* *}$ \\
& Sig. (2-tailed) & &, 000 &, 008 &, 000 &, 000 \\
& N & 97 & 97 & 97 & 97 & 97 \\
\hline X4.2 & Pearson Correlation & $.686^{* *}$ & 1 & $.436^{* *}$ & $.477^{* *}$ & $.850^{* *}$ \\
& Sig. (2-tailed) &, 000 & &, 000 &, 000 &, 000 \\
& N & 97 & 97 & 97 & 97 & 97 \\
\hline X4.3 & Pearson Correlation & $.268^{* *}$ & $.436^{* *}$ & 1 & $.355^{* *}$ & $.673^{* *}$ \\
& Sig. (2-tailed) &, 008 &, 000 & &, 000 &, 000 \\
& N & 97 & 97 & 97 & 97 & 97 \\
\hline X4.4 & Pearson Correlation & $.456^{* *}$ & $.477^{* *}$ & $.355^{* *}$ & 1 & $.754^{* *}$ \\
& Sig. (2-tailed) &, 000 &, 000 &, 000 & &, 000 \\
& N & 97 & 97 & 97 & 97 & 97 \\
\hline Jaminan & Pearson Correlation & $.781^{* *}$ & $.850^{* *}$ & $.673^{* *}$ & $.754^{* *}$ & 1 \\
& Sig. (2-tailed) &, 000 &, 000 &, 000 &, 000 & \\
& N & 97 & 97 & 97 & 97 & 97 \\
\hline
\end{tabular}

Sumber : Output SPSS17.0,2019

\section{e. Empati}

Hasil uji validitas variabel empati dapat dilihat pada tabel 16 berikut:

Tabel 16; Hasil Uji Validitas Variabel Empati

\begin{tabular}{ll|r|r|r|r|r|}
\hline & X5.1 & X5.2 & X5.3 & X5.4 & Empati \\
\hline X5.1 & Pearson Correlation & 1 & $.686^{* *}$ & $.507^{* *}$ & $.461^{* *}$ & $.818^{* *}$ \\
& Sig. (2-tailed) & &, 000 &, 000 &, 000 &, 000 \\
& N & 97 & 97 & 97 & 97 & 97 \\
\hline X5.2 & Pearson Correlation & $.686^{* *}$ & 1 & $.512^{* *}$ & $.518^{* *}$ & $.846^{* *}$
\end{tabular}


Pengaruh Kualitas Layanan... (Rani, Basalamah \& Damis) | 108

\begin{tabular}{llrrrrr} 
& Sig. (2-tailed) &, 000 & &, 000 &, 000 &, 000 \\
& N & 97 & 97 & 97 & 97 & 97 \\
\hline X5.3 & Pearson Correlation & $.507^{* *}$ & $.512^{* *}$ & 1 & $.535^{* *}$ & $.775^{* *}$ \\
& Sig. (2-tailed) &, 000 &, 000 & &, 000 &, 000 \\
& N & 97 & 97 & 97 & 97 & 97 \\
\hline X5.4 & Pearson Correlation & $.461^{* *}$ & $.518^{* *}$ & $.535^{* *}$ & 1 & $.791^{* *}$ \\
& Sig. (2-tailed) &, 000 &, 000 &, 000 & &, 000 \\
& N & 97 & 97 & 97 & 97 & 97 \\
\hline Empati & Pearson Correlation & $.818^{* *}$ & $.846^{* *}$ & $.775^{* *}$ & $.791^{* *}$ & 1 \\
& Sig. (2-tailed) &, 000 &, 000 &, 000 &, 000 & \\
& N & 97 & 97 & 97 & 97 & 97 \\
\hline
\end{tabular}

Sumber : Output SPSS17.0,2019

\section{Uji Reliabilitas}

Tabel 18; Hasil Uji Reliabilitas

\begin{tabular}{lrc}
\hline \multicolumn{1}{c|}{ Variabel } & Koefisien alpha & Keterangan \\
\hline Bukti Fisik &, 862 & Reliabel \\
Kehandalan &, 853 & Reliabel \\
Ketanggapan &, 843 & Reliabel \\
Jaminan Mutu Pelayanan &, 863 & Reliabel \\
Empati &, 849 & Reliabel \\
Kepuasan &, 859 & Reliabel \\
\hline
\end{tabular}

Sumber : Output SPSS17.0,2019

\section{B. Hasil Penelitian}

\section{Uji Regresi Linear Berganda}

Tabel 19; Hasil Uji Regresi Linear Berganda

\begin{tabular}{ll|r|r}
\hline \multirow{2}{*}{ Model } & \multicolumn{2}{|c}{ Unstandardized Coefficients } \\
\cline { 3 - 4 } & \multicolumn{2}{c}{ B } & \multicolumn{2}{c}{ Std. Error } \\
\hline 1 & (Constant) & 6,374 &, 799 \\
& Bukti Fisik &, 422 &, 119 \\
& Kehandalan &, 073 &, 121 \\
Ketanggapan &, 376 &, 127 \\
& Jaminan Mutu Pelayanan &,- 119 &, 120 \\
Empati &, 128 & \\
\hline
\end{tabular}

Sumber : Output SPSS17.0,2019

Pada tabel 19 tampak nilai masing-masing variabel independen sehingga diperoleh persamaan regresinya sebagai berikut:

$Y=6,374+0,422 X_{1}+0,073 X_{2}+0,376 X_{3}-0,119 X_{4}+0,128 X_{5}$

Dari persamaan diatas, diperoleh nilai konstanta sebesar 6,374 , hal ini menunjukkan bahwa jika tidak ada perubahan nilai variabel indenpenden (bukti fisik (X1), kehandalan (X2), ketanggapan (X3), jaminan (X4) empati (X5)), maka kepuasan pasien rawat inap Private Care Center (PCC) RSUP Dr. Wahidin Sudirohusodo Makassar akan tetap sebesar 6,374. 


\section{Koefisien Determinasi $\left(\mathbf{R}^{2}\right)$}

Tabel 20; Koefisien Determinasi $\left(\mathrm{R}^{2}\right)$

\begin{tabular}{|c|c|c|c|c|}
\hline Model & $\mathrm{R}$ & $\mathrm{R}$ Square & $\begin{array}{c}\text { Adjusted R } \\
\text { Square }\end{array}$ & $\begin{array}{c}\text { Std. Error of the } \\
\text { Estimate }\end{array}$ \\
\hline 1 & $.724^{\mathrm{a}}$ &, 524 &, 498 & 1,440 \\
\hline
\end{tabular}

Sumber : Output SPSS17.0,2019

Pada tabel 20 tampak bahwa nilai $\mathrm{R}$ Square yang diperoleh sebesar 0,524 menunjukkan kepuasan pasien rawat inap Private Care Center (PCC) RSUP Dr. Wahidin Sudirohusodo dipengaruhi oleh lima variabel yaitu bukti fisik, kehandalan, ketanggapan, jaminan, dan empati sebesar 52,4\%, dan 47,6\% dipengaruhi oleh variabel lain yang belum diteliti dalam penelitian ini. Pengaruh variabel-variabel indenpenden terhadap variabel dependen dalam penelitian ini cukup tinggi yaitu $52,4 \%$.

\section{Pegujian Simultan (Uji F)}

Tabel 21; Hasil Pengujian Simultan (Uji F)

\begin{tabular}{|c|c|c|c|c|c|c|}
\hline & Model & $\begin{array}{l}\text { Sum of } \\
\text { Squares }\end{array}$ & $\mathrm{df}$ & $\begin{array}{l}\text { Mean } \\
\text { Square }\end{array}$ & $\mathrm{F}$ & Sig. \\
\hline \multirow[t]{3}{*}{1} & Regression & 207,555 & 5 & 41,511 & 20,026 & $.000^{\mathrm{a}}$ \\
\hline & Residual & 188,631 & 91 & 2,073 & & \\
\hline & Total & 396,186 & 96 & & & \\
\hline
\end{tabular}

Sumber : Output SPSS17.0,2019

Pada tabel 21 tampak bahwa nilai signifikansi F sebesar 0,000. Berdasarkan kriteria pengujian, jika nilai probabilitas $<0,1$ maka $\mathrm{H}_{\mathrm{a}}$ diterima. Dari tabel di atas diperoleh bahwa variabel bukti fisik, kehandalan, ketanggapan, jaminan, dan empati secara bersamaan berpengaruh signifikan terhadap kepuasan pasien rawat inap Private Care Center (PCC) RSUP Dr. Wahidin Sudirohusodo. Jika bukti fisik, kehandalan, ketanggapan, jaminan, dan empati secara bersamaan meningkat maka kepuasan pasien rawat inap Private Care Center (PCC) RSUP Dr. Wahidin Sudirohusodo akan mengalami peningkatan pula.

\section{Uji Parsial (Uji t)}

Tabel 22; Hasil Pengujian Parsial (Uji t)

\begin{tabular}{|ll|rr|r|r|r|}
\hline \multirow{2}{*}{ Model } & \multicolumn{2}{|c|}{$\begin{array}{c}\text { Unstandardized } \\
\text { Coefficients }\end{array}$} & $\begin{array}{c}\text { Standardized } \\
\text { Coefficients }\end{array}$ & \multirow{2}{*}{$\mathrm{t}$} & \multirow{2}{*}{ Sig. } \\
\cline { 2 - 4 } & \multicolumn{1}{|c|}{$\mathrm{B}$} & Std. Error & \multicolumn{2}{c|}{ Beta } & & \\
\hline 1 & (Constant) & 6,374 & 1,799 & & 3,543 &, 001 \\
& Bukti Fisik &, 422 &, 091 &, 413 & 4,637 &, 000 \\
Kehandalan &, 073 &, 119 &, 065 &, 610 &, 544 \\
Ketanggapan &, 376 &, 121 &, 338 & 3,106 &, 003 \\
Jaminan &,- 119 &, 127 &,- 094 &,- 938 &, 351 \\
Empati &, 128 &, 120 &, 115 & 1,064 &, 290 \\
\hline
\end{tabular}

Sumber : Output SPSS17.0,2019 
Pada tabel 22 tampak bahwa bukti fisik berpengaruh dan signifikan terhadap kepuasan pasien rawat inap Private Care Center (PCC) RSUP Dr. Wahidin Sudirohusodo secara parsial. Hal ini dibuktikan dengan tingkat signifikansi <0,05 yaitu sebesar 0,000 dan hipotesis $\mathrm{H}_{\mathrm{a}}$ diterima.

Kehandalan tidak berpengaruh terhadap kepuasan pasien rawat inap Private Care Center (PCC) RSUP Dr. Wahidin Sudirohusodo secara parsial. Hal ini dibuktikan dengan tingkat signifikansi $>0,05$ yaitu sebesar 0,544 dan hipotesis $\mathrm{H}_{\mathrm{a}}$ ditolak.

\section{PEMBAHASAN}

Hasil penelitian dengan uji statistik yang telah dilakukan menunjukkan bahwa terdapat pengaruh dan hubungan yang kuat antara bukti fisik dan ketanggapan terhadap kepuasan pasien rawat inap Private Care Center (PCC) RSUP Dr. Wahidin Sudirohusodo. Sedangkan Kehandalan, Jaminan, dan Empati menunjukkan bahwa tidak terdapat pengaruh dan hubungan terhadap kepuasan pasien rawat inap Private Care Center (PCC) RSUP Dr. Wahidin Sudirohusodo.

\section{Pengaruh Bukti Fisik terhadap kepuasan pasien rawat inap Private Care Center (PCC) RSUP Dr. Wahidin Sudirohusodo}

Berdasarkan hasil uji parsial yang telah dilakukan antara bukti fisik sebagai variabel independen X1 terhadap kepuasan pasien rawat inap Private Care Center (PCC) RSUP Dr. Wahidin Sudirohusodo sebagai variabel dependen Y menunjukkan bahwa t hitung sebesar 4,637 dengan nilai signifikansi sebesar 0,000<0,05 dan hasil uji regresi linear berganda menunjukkan nilai koefisien sebesar 0,422. Hal ini berarti bahwa variabel bukti fisik berpengaruh signifikan dan paling dominan terhadap kepuasan pasien rawat inap Private Care Center (PCC) RSUP Dr. Wahidin Sudirohusodo secara parsial.

Hasil penelitian ini sejalan pula dengan penelitian yang dilakukan oleh (Like J. Mumu, Grace D. Kandou, dan Diana V. Doda, 2015) dengan judul Analisis FaktorFaktor Yang Berhubungan Dengan Kepuasan Pasien di Poliklinik Penyakit Dalam RSUP Prof. Dr. R.D. Kandou Manado dengan hasil penelitian menyatakan bahwa terdapat hubungan yang signifikan antara bukti fisik dengan kepuasan pasien di Poliklinik Penyakit Dalam RSUP Prof. Dr. R. D. Kandou Manado. Penelitian oleh (Meutia Dewi, 2013) dengan judul Pengaruh Kualitas Pelayanan terhadap Kepuasan Pasien Pengguna BPJS pada Rumah Sakit Rehabilitasi Medik Kabupaten Aceh Timur dengan hasil penelitian menunjukkan bahwa bukti fisik mempunyai pengaruh secara signifikan terhadap Kepuasan Pasien Pengguna BPJS pada Rumah Sakit Rehabilitasi Medik Kabupaten Aceh Timur.

\section{Pengaruh Kehandalan terhadap kepuasan pasien rawat inap Private Care Center (PCC) RSUP Dr. Wahidin Sudirohusodo}

Berdasarkan hasil uji parsial yang telah dilakukan antara kehandalan sebagai variabel independen X2 terhadap kepuasan pasien rawat inap Private Care Center (PCC) RSUP Dr. Wahidin Sudirohusodo sebagai variabel dependen Y menunjukkan bahwa $t$ hitung sebesar 0,610 dengan nilai signifikansi sebesar 0,544>0,05 dan hasil uji regresi linear berganda menunjukkan nilai koefisien sebesar 0,073. Hal ini berarti bahwa variabel kehandalan berpengaruh positif dan tidak signifikan terhadap 
kepuasan pasien rawat inap Private Care Center (PCC) RSUP Dr. Wahidin Sudirohusodo.

Hasil penelitian ini sejalan pula dengan penelitian yang dilakukan oleh Dewi (2010) dengan judul Analisis Pengaruh Tingkat Kualitas Pelayanan Jasa Puskesmas Terhadap Kepuasan Pasien (Studi pada Puskesmas Gunungpati Semarang) dengan hasil penelitian menunjukkan bahwa kehandalan berpengaruh positif dan signifikan terhadap kepuasan konsumen tidak terbukti. Hal yang sama dikemukan oleh Ade Resky Aprilyani, Nurhayani, dan Yusri Abadi (2016) dengan judul Hubungan Mutu Pelayanan Kesehatan dengan Kepuasan Pasien Rawat Jalan di Puskesmas Antang Kota Makassar dengan hasil penelitian menyatakan bahwa tidak ada hubungan antara keandalan (reliability) dengan kepuasan pasien rawat jalan di Puskesmas Antang Kota Makassar tahun 2016.

\section{Pengaruh Ketanggapan terhadap kepuasan pasien rawat inap Private Care Center (PCC) RSUP Dr. Wahidin Sudirohusodo}

Berdasarkan hasil uji parsial yang telah dilakukan antara ketanggapan sebagai variabel independen X1 terhadap kepuasan pasien rawat inap Private Care Center (PCC) RSUP Dr. Wahidin Sudirohusodo sebagai variabel dependen Y menunjukkan bahwa $t$ hitung sebesar 3,106 dengan nilai signifikansi sebesar 0,003<0,05 dan hasil uji regresi linear berganda menunjukkan nilai koefisien sebesar 0,376 . Hal ini berarti bahwa variabel ketanggapan berpengaruh positif dan signifikan terhadap kepuasan pasien rawat inap Private Care Center (PCC) RSUP Dr. Wahidin Sudirohusodo secara parsial.

Hasil penelitian ini sejalan pula dengan penelitian yang dilakukan oleh (Rolando Jacobis, 2013) dengan judul penelitian Faktor-Faktor Kualitas Pelayanan Pengaruhnya Terhadap Kepuasan Pasien Rawat Inap Peserta Jamkesmas di BLU RSUP PROF.DR. R.D. Kandou Manado dengan hasil penelitian menunjukkan bahwa ketanggapan dalam pelayanan berpengaruh terhadap kepuasan pasien rawat inap. Hal yang sama dikemukakan oleh Like J. Mumu, Grace D. Kandou, dan Diana V. Doda (2015) dengan judul Analisis Faktor-Faktor Yang Berhubungan Dengan Kepuasan Pasien di Poliklinik Penyakit Dalam RSUP Prof. Dr. R.D. Kandou Manado dengan hasil analisis menunjukkan daya tanggap merupakan dimensi mutu yang paling dominan dalam hubungan dengan kepuasan pasien di Poliklinik Penyakit Dalam RSUP Prof. Dr. R. D. Kandou Manado.

\section{Pengaruh Jaminan terhadap kepuasan pasien rawat inap Private Care Center (PCC) RSUP Dr. Wahidin Sudirohusodo}

Berdasarkan hasil uji parsial yang telah dilakukan antara jaminan sebagai variabel independen X2 terhadap kepuasan pasien rawat inap Private Care Center (PCC) RSUP Dr. Wahidin Sudirohusodo sebagai variabel dependen Y menunjukkan bahwa t hitung sebesar -0,938 dengan nilai signifikansi sebesar 0,351>0,05 dan hasil uji regresi linear berganda menunjukkan nilai koefisien sebesar -0,119. Hal ini berarti bahwa variabel jaminan tidak berpengaruh positif dan tidak signifikan terhadap kepuasan pasien rawat inap Private Care Center (PCC) RSUP Dr. Wahidin Sudirohusodo. 
Hasil penelitian ini sejalan pula dengan penelitian yang dilakukan oleh (Winston I. Kaban, G. D. Kandou. S, dan L. H. V. J. Lapian, 2015) dengan judul Kepuasan Pasien Di Instalasi Gawat Darurat RSUP Prof. Dr. R. D. Kandou Manado dengan hasil penelitian menunjukkan bahwa tidak terdapat hubungan yang signifikan antara jaminan terhadap kepuasan pasien di Instalasi Gawat Darurat RSUP Prof. Dr. R. D. Kandou Manado. Hal yang sama dikemukan oleh (Adriansyah, Syamsul Bahri, dan Ira Nuriya Santi, 2017) dengan judul Kualitas Pelayanan Terhadap Kepuasan Pasien di RSUD Morowali Kecamatan Bungku Tengah dengan hasil penelitian menyatakan bahwa jaminan secara parsial tidak berpengaruh signifikan terhadap kepuasan pasien RSUD Morowali Kecamatan Bungku Tengah.

\section{Pengaruh Empati terhadap kepuasan pasien rawat inap Private Care Center (PCC) RSUP Dr. Wahidin Sudirohusodo}

Berdasarkan hasil uji parsial yang telah dilakukan antara empati sebagai variabel independen X2 terhadap kepuasan pasien rawat inap Private Care Center (PCC) RSUP Dr. Wahidin Sudirohusodo sebagai variabel dependen Y menunjukkan bahwa t hitung sebesar 1,064 dengan nilai signifikansi sebesar 0,290>0,05 dan hasil uji regresi linear berganda menunjukkan nilai koefisien sebesar 0,128. Hal ini menunjukkan bahwa variabel empati berpengaruh positif dan tidak signifikan terhadap kepuasan pasien rawat inap Private Care Center (PCC) RSUP Dr. Wahidin Sudirohusodo.

Hasil penelitian ini sejalan pula dengan penelitian yang dilakukan oleh (Sulviandani, Syamsul Bachri, dan Rahmat Mubaraq, 2018) dengan judul penelitian Pengaruh Dimensi Kualitas Layanan Terhadap Kepuasan Pasien Rawat Inap di Rumah Sakit Umum Daerah Morowali dengan hasil penelitian menunjukkan bahwa Empati (X5) berpengaruh tidak signifikan terhadap kepuasan pasien rawat inap di RSUD Morowali. Hal yang sama dikemukan oleh Sudarmin Manik (2016) dengan judul Pengaruh Kualitas Pelayanan Terhadap Kepuasan Pasien Padarumah Sakit Thursina di Duri dengan hasil penelitian menyatakan bahwa empaty tidak berpengaruh signifikan terhadap kepuasan pasien Rumah Sakit Thursina Duri.

\section{SIMPULAN DAN SARAN}

A. Simpulan

1. Pengujian terhadap hipotesis bahwa bukti fisik (tangibles) berpengaruh signifikan dan paling dominan terhadap kepuasan pasien di rawat inap Private Care Center (PCC) RSUP dr. Wahidin Sudirohusodo Makassar diterima.

2. Pengujian terhadap hipotesis bahwa kehandalan (reliablility) berpengaruh signifikan terhadap kepuasan pasien di rawat inap Private Care Center (PCC) RSUP dr. Wahidin Sudirohusodo Makassar ditolak.

3. Pengujian terhadap hipotesis ketanggapan (responsiveness) berpengaruh signifikan terhadap kepuasan pasien di rawat inap Private Care Center (PCC) RSUP dr. Wahidin Sudirohusodo Makassar diterima.

4. Pengujian terhadap hipotesis jaminan (assurance) berpengaruh negatif dan tidak signifikan terhadap kepuasan pasien di rawat inap Private Care Center (PCC) RSUP dr. Wahidin Sudirohusodo Makassar ditolak. 
5. Pengujian terhadap hipotesis empati (empathy) berpengaruh positif dan tidak signifikan terhadap kepuasan pasien di rawat inap Private Care Center (PCC) RSUP dr. Wahidin Sudirohusodo Makassar ditolak.

6. Pengujian terhadap hipotesis Empati (empathy) merupakan variabel yang dominan mempengaruhi kepuasan pasien rawat inap di ruang perawatan Private Care Center (PCC) RSUP Dr. Wahidin Sudirohusodo Makassar ditolak.

\section{B. Saran-saran}

Berdasarkan hasil penelitian yang diperoleh bahwa terdapat pengaruh yang positif dan signifikan antara bukti fisik dan ketanggapan terhadap kepuasan pasien rawat inap di ruang perawatan Private Care Center (PCC) RSUP Dr. Wahidin Sudirohusodo Makassar serta tidak terdapat pengaruh positif dan signifikan antara kehandalan, jaminan, dan empati, maka dalam hal ini dapat diberikan saran-saran sebagai berikut:

1. Untuk lebih giat melakukan pemahaman terkait bukti fisik, kehandalan, ketanggapan, jaminan, dan empati kepada pegawai terkhusus kepada pegawai yang masih baru agar kepuasan pasien dapat meningkat.

2. Penampilan sarana, pra sarana, petugas, dan ketangggapan dalam memberikanpelayanan kepada pasien harus dapat dipertahankan bahkan ditingkatkan karena merupakan tolak ukur kepuasan bagi pasien.

3. Kehandalan, jaminan, dan empati dari petugas dalam memberikan pelayanan harus ditingkatkan dengan mengacu kepada SOP yang berlaku agar pasien dapat merasa yakin terhadap kualitas pelayanan didapatkan.

4. Diharapkan kepada pimpinan RSUP Dr. Wahidin Sudirohusodo Makassar, agar kepuasan pasien terhadap pelayanan ditingkatkan dengan tidak henti-hentinya melakukan inovasi.

5. RSUP Dr. Wahidin Sudirohusodo diharapkan mampu memberi pelayanan yang memuaskan kepada seluruh pasien dengan menerapkan standar pelayanan nasional dan internasional.

6. Bagi peneliti lain, hasil penelitian ini dapat digunakan sebagai data untuk melakukan penelitian sejenis tentang faktor-faktor yang mempengaruhi kepuasan pasien.

\section{DAFTAR PUSTAKA}

Adriansyah, Syamsul B, dan Ira S. S, (2017). Kualitas Pelayanan Terhadap Kepuasan Pasien di RSUD Morowali Kecamatan Bungku Tengah.

Arikunto, S, (2002). Metodologi Penelitian Suatu Pendekatan Proposal. Penerbit PT. Rineka Cipta, Jakarta.

Assauri, S, (2003). Customer Service yang Baik Landasan Pencapaian Customer Satisfaction dalam Usahawan, No. 01, Tahun XXXII, Januari, hal.25-30: Jakarta.

Azwar, S, (1996). Reliabilitas dan Validitas. Edisi ketiga. Pustaka Pelajar, Yogyakarta.

Bustan, J, (2012). Pengaruh Kualitas Pelayanan Terhadap Kepuasan Pasien Pada Rumah Sakit Pemerintah Dan Swasta Di Kota Palembang. Jurnal Orasi Bisnis Edisi Ke-Vii, Mei 2012, 84-92.

Dewi, (2010). Analisis Pengaruh Tingkat Kualitas Pelayanan Jasa Puskesmas 
Terhadap Kepuasan Pasien (Studi pada Puskesmas Gunungpati Semarang).

Jacobalis, S, (1995). Liberalisasi Bisnis Jasa Kesehatan dan Dampaknya Bagi Rumah Sakit Indonesia. Jakarta: IRSJAM XXXVII.

John, J., (1992). Patient Satisfaction: The Impact of Past Exdperience. JHCM. Vol12. No. 3. pp 56-64.

Kotler, Philip dan Keller, K.L., (2007). "Manajemen Pemasaran," Edisi 12, Indeks; Jakarta.

Like J. M., Grace D. K., dan Diana V. D, (2015). Analisis Faktor-Faktor Yang Berhubungan Dengan Kepuasan Pasien di Poliklinik Penyakit Dalam RSUP Prof. Dr. R.D. Kandou Manado.

Mulyadi, D., Fadli, U, M., Ningsih F.C.K, (2013). Analisis Manajemen Mutu Pelayanan Kesehatan Pada Rumah Sakit Islam Karawang. Tidak ada Nama Universitas.

Parasuraman, A. Z., V. A, Berry, L, L, (1998). SERVQUAL: A Multiple item scale for measuring consumer perception of service quality. Journal of Retailing Vol 64 No I pp 12-40.

Rolando J, (2013). Faktor-Faktor Kualitas Pelayanan Pengaruhnya Terhadap Kepuasan Pasien Rawat Inap Peserta Jamkesmas di BLU RSUP Prof. DR. R.D. Kandou Manado.

S. Supriyanto dan Ernawati, (2010). Judul: Pemasaran Industri Jasa Kesehatan. Penerbit CV Andi Offset: Yogyakarta

Sugiyono, (2004). "Metode Penelitian Bisnis". Penerbit Alfabeta, Bandung.

Sugiyono, (2008). Metode Penelitian Kunatitatif Kualitatif dan R\&D. Penerbit Alfabeta, Bandung.

Sulviandani, S.B, dan Rahmat M., (2018). Pengaruh Dimensi Kualitas Layanan Terhadap Kepuasan Pasien Rawat Inap di Rumah Sakit Umum Daerah Morowali.

Supriyanto, S. \& R. D. Wulandari, (2011). “Manajemen Mutu Pelayanan Kesehatan.", Health Advocacy. Penerbit Pohon Cahaya, Surabaya.

Waworuntu, B, (1997). Dasar-dasar Keterampilan Abdi Negara Melayani.

Winston I. K., G. D. Kandou. S, dan L. H. V. J. Lapian, (2015). Kepuasan Pasien Di Instalasi Gawat Darurat RSUP Prof. Dr. R. D. Kandou Manado.

Wildan, A, A, H. \& Alimul, A., (2008). "Dokumentasi Kebidanan. Penerbit Salemba Medika, Jakarta. 